\title{
The high-performance technology CRISPR/Cas9 improves knowledge and management of acute myeloid leukemia
}

\author{
Romeo Gabriel Mihaila ${ }^{\mathrm{a}, \mathrm{b}}$, Diana Topircean ${ }^{\mathrm{b}}$
}

Knowledge on acute myeloid leukemia pathogenesis and treatment has progressed recently, but not enough to provide ideal management. Improving the prognosis of acute myeloid leukemia patients depends on advances in molecular biology for the detection of new therapeutic targets and the production of effective drugs. The CRISPR/Cas9 technology allows gene insertions and deletions and it is the first step in investigating the function of their encoded proteins. Thus, new experimental models have been developed and progress has been made in understanding protein metabolism, antitumor activity, leukemic cell maintenance, differentiation, growth, apoptosis, and self-renewal, the combined pathogenetic mechanisms involved in leukemogenesis. The CRISPR/Cas9 system is used to understand drug resistance and find solutions to overcome it. The therapeutic progress achieved using the CRISPR/Cas9 system is remarkable. FST gene removal inhibited acute myeloid leukemia cell growth. Lysine acetyltransferase gene deletion contributed to decreased proliferation rate, increased apoptosis, and favored differentiation of acute myelid leukemia cells carrying MLL-X gene fusions. The removal of $C D 38$ gene from NK cells decreased NK fratricidal cells contributing to increased efficacy of new CD38 CAR-NK cells to target leukemic blasts. BCL2 knockout has synergistic effects with FLT3 inhibitors. Exportin 1 knockout is synergistic with midostaurin treatment in acute myeloid leukemia with FLT3-ITD mutation. Using the results of CRISPR/Cas9 libraries and technology application will allow us to get closer to achieving the goal of curing acute myeloid leukemia in the coming decades.

Key words: acute myeloid leukemia, BCL2, CD38, CRISPR/Cas9, FLT3 inhibitors, IDH2

Received: May 7, 2021; Revised: July 13, 2021; Accepted: July 14, 2021; Available online: August 24, 2021

https://doi.org/10.5507/bp.2021.048

(c) 2021 The Authors; https://creativecommons.org/licenses/by/4.0/

${ }^{a}$ Faculty of Medicine, "Lucian Blaga" University of Sibiu, Romania

${ }^{b}$ Department of Hematology, Emergency County Clinical Hospital Sibiu, Romania

Corresponding author: Romeo Gabriel Mihaila, e-mail: romeomihaila@yahoo.com

\section{INTRODUCTION}

Acute myeloid leukemia (AML) is an aggressive malignant hemopathy. Its prognosis continues to be poor with the current standard of care, as in many patients, the disease relapses or becomes refractory ${ }^{1}$. It is unanimously accepted that new therapies are needed to improve AML patients survival ${ }^{2}$.

Clustered regularly interspaced short palindromic repeats (CRISPR) / CRISPR-associated protein 9 (Cas9) is one of the new technologies in molecular biology that together with the engineering techniques of humanized physiologically relevant animal models are the foundation of a new genomics era that allows the expansion of a previously unsuspected magnitude of knowledge about the pathophysiology of AML. New knowledge of descriptive and functional genomics are the prerequisites that will increasingly contribute to achieving the goal of curing AML in the coming decades ${ }^{3}$.

The CRISPR-Cas9 system has been used in recent years for gene insertions or deletions into the genome of eukaryotic cells. The technique consists of designing specific "single guide RNAs" (sgRNAs) that aim to recognize specific genomic sequences known as PAM sites (Fig. 1). When both Cas9 proteins and sgRNA are introduced into a cell, small deletions occur adjacent to the PAM site through doublestranded DNA breaks. This technique has been conceived to inhibit the expression of single or multiple genetic loci wherein it removes specific DNA sequences. The result is a nonfunctional gene $e^{4}$. The small nucleotide insertions or deletions obtained using the CRISPR-Cas9 technique do not always produce a nonfunctional gene, but one that encodes a functionally active protein. This can reduce the therapeutic efficiency. An improvement in the outcome of gene therapy can be achieved with an sgRNA-targeting splicing site ${ }^{5}$. The CRISPR/Cas9 technology can be optimized, as it has been quite recently introduced in practice ${ }^{4}$.

CRISPR/Cas9 libraries were used to identify effector genes whose role was not known in AML. These AMLrelated genes are involved in various cellular pathogenetic mechanisms, such as signaling transduction, energy metabolism, transcriptional regulation, and epigenetics. This high-performance technology allows the identification of genes that may be candidates for pharmaceutical targeting $^{6}$. 


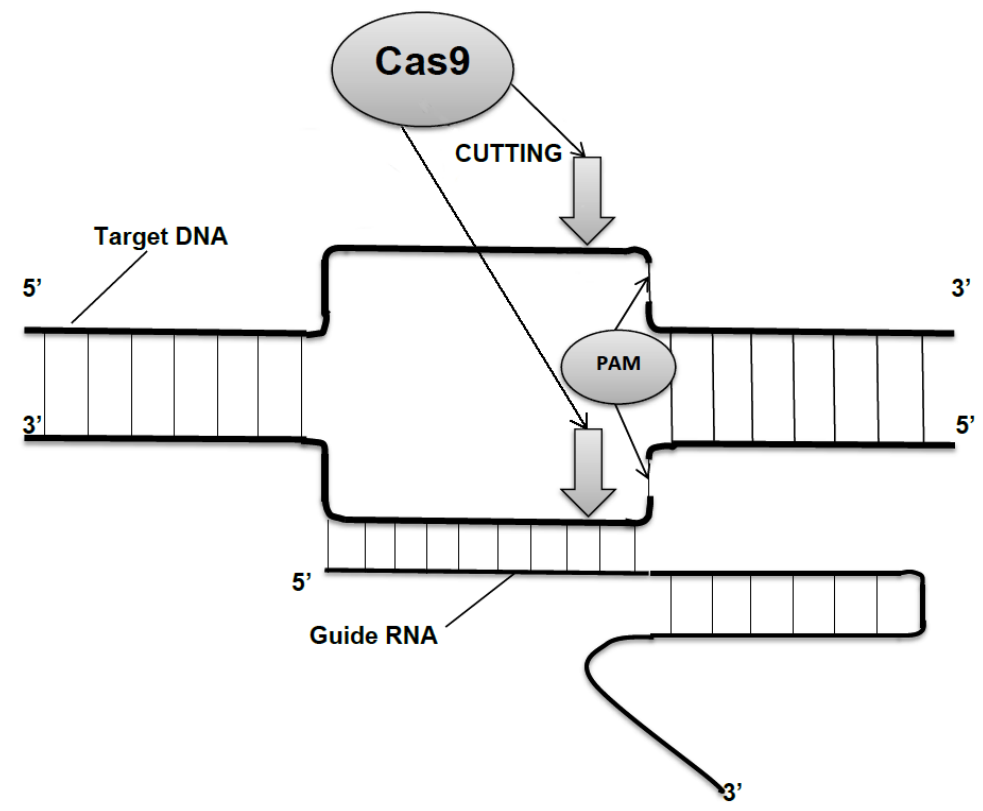

Fig. 1. The components of the CRISPR/Cas9 system. Guide RNA attaches specifically to the DNA fragment. Cas9 (CRISPRassociated protein 9) is an endonuclease that can cut the double-stranded DNA. This process requires PAM (protospacer adjacent motif) - a specific sequence of DNA located at the 3' end of the RNA guide. DNA repair after sectioning can be done through two pathways: non-homologous end joining (which leads to a random insertion / deletion of DNA), or homology directed repair (which produces a precise editing of the genome).

\section{EXPERIMENTAL MODELS}

Oncogenesis is the result of somatic mutations that occur sequentially and produce successive clonal populations. Such a clonal evolution model of AML was obtained using induced pluripotent stem cells (iPSC) and CRISPR/Cas9 technology. After three driver mutations were introduced step by step, iPSC lines were obtained. After hematopoietic differentiation occurred, cells showed distinct premalignant stages, such as clonal hematopoiesis and myelodysplastic syndrome, culminating in a leukemia which could be transplanted. An early and persistent event in the process of leukemogenesis was a dysregulation of inflammatory signaling, which was cell-autonomous. It could serve as a therapeutic target ${ }^{7}$. Using CRISPR/Cas9 system it has been established that loss of the FBXO11 protein, which is part of the SCF ubiquitin ligase complex, produces cytokine independent growth of MDS-L cells. In addition, FBXO11 expression is decreased in patients with secondary AML. It can be concluded that loss of FBXO11 allows the progression of MDS to AML (ref. ${ }^{8}$ ).

$\mathrm{N}$-terminally truncated short form of GATA1 is the result of a mutation in the gene encoding the GATA1 in children with Down syndrome in whom AML occurs. CRISPR/Cas9 technology was used to introduce GATA1 mutation in some induced pluripotent stem cell lines. The presence of short form of GATA1, without full-length GATA1, decreased the erythropoiesis, whereas megacariopoiesis and granulopoiesis increased, characters of transient abnormal myelopoiesis, which presents pre-leukemic characteristics?.

Mixed lineage leukemia (MLL)-AF9 (MA9) chromosomal rearrangements were induced in murine hematopoietic stem cells using CRISPR/Cas9 system. The result was higher rate of clonogenicity, enrichment of c-Kit-positive leukemic stem cells and higher expression of MA9 target gene. This is a novel cellular model of MA9 leukemia obtained in an experimental model and progenitor cells ${ }^{10}$. The same technology was used to create a model of MLL KMT2A rearrangements (KMT2Ar) in hematopoietic stem and progenitor cells (HSPCs) obtained from human cord blood (huCB). The genome-edited KMT2Ar cells obtained from infant and adult showed indefinite growth potential except for MLL-AF4 huBM cells whose proliferation stopped after 80 days. FFAR2 (an epigenetic tumor suppressor) could be responsible for the failure of MLL-AF4 to immortalize adult cells under myeloid conditions ${ }^{11}$.

The effects of gene deletion obtained by CRISPR/ Cas9 technology on AML cell metabolism are presented in Table 1.

\section{PROTEIN METABOLISM}

Ubiquitylation consists of an enzymatic post-translational modification by which a ubiquitin protein is attached to a protein substrate. Ubiquitination is involved in protein metabolism, including by regulating the degradation of proteins. TAK-243 is an inhibitor of ubiquitinlike modifier activating enzyme 1 , involved in ubiquitin activation. A CRISPR/Cas9 knockout screen was used to find genes essential for TAK-243 action in AML cells. Thus, BEN domain-containing protein 3 (BEND3) has been identified, which represses transcription and regulates chromatin organization. Knockout of these gene produces resistance to TAK-243 both in vitro and in vivo. The mechanism of resistance to TAK-243: BEND3 knock- 
Table 1. The effects of gene deletion obtained by CRISPR/Cas9 technology on AML cell metabolism.

\begin{tabular}{|c|c|c|c|}
\hline No & Gene deleted & The result of the knockout of the gene & Ref. \\
\hline 1 & FBXO11 & allows the progression of MDS to AML & 8 \\
\hline 2 & BEND3 & $\begin{array}{l}\text { resistance to TAK-243 (an inhibitor of ubiquitin-like modifier activat- } \\
\text { ing enzyme 1) }\end{array}$ & 12 \\
\hline 3 & $I L F 2 / I L F 3$ & $\begin{array}{l}\text { reduces the production of full-length cereblon protein, and decreases } \\
\text { the response to CC- } 90009 \text { (a modulator of cereblon) }\end{array}$ & 13 \\
\hline 4 & $C B L B$ & stem cells differentiate into PNK cells & 14 \\
\hline 5 & deletion of 47 base pairs of the $C B S 7 / 9$ & dowregulates the HOXA9 and sensitizes the BETi treatment reaction & 16 \\
\hline 6 & IRF-1 & $\begin{array}{l}\text { upregulates the } \mathrm{p} 47 \text { phox expression required for mature-cell ROS pro- } \\
\text { duction in granulocyte metabolism }\end{array}$ & 18 \\
\hline 7 & CBFA2T3 & $\begin{array}{l}\text { spontaneous and ATRA-induced activation of myeloid genes involved } \\
\text { in myeloid differentiation }\end{array}$ & 19 \\
\hline 8 & $K L F 4$ & $\begin{array}{l}\text { reduce cell growth and increase apoptosis in two cell lines: NB4 and } \\
\text { MonoMac- } 6\end{array}$ & 1 \\
\hline 9 & $L K B 1 / S T K 11$ & suppression of the progression of myeloproliferative neoplasms & 21 \\
\hline 10 & CXCR-4 & eradicates AML cells & 24 \\
\hline 11 & TRPM2 & $\begin{array}{l}\text { inhibition of leukemic proliferation and survival and increased sensitiv- } \\
\text { ity to doxorubicin }\end{array}$ & 26 \\
\hline 12 & MTCH2 & $\begin{array}{l}\text { reduced growth and engraftment potential of stem cells, and increased } \\
\text { differentiation }\end{array}$ & 27 \\
\hline 13 & DNMT3b & promoter hypomethylation and high expression of HOTAIRM1 & 29 \\
\hline 14 & МYH8 & $\begin{array}{l}\text { higher migration capacity, epithelial-to-mesenchymal transition, cell } \\
\text { migration and a repression of the Raf / MAPK mechanism }\end{array}$ & 31 \\
\hline 15 & $M N 1$ & $\begin{array}{l}\text { decreases the transcription of } H O X A 9 \text { and } H O X A 10 \text { genes, and their } \\
\text { target genes such as BCL2, MCL1 and Survivin }\end{array}$ & 32 \\
\hline
\end{tabular}

AML - acute myeloid leukemia; $B C L 2$ - B-cell lymphoma 2; BEND3 - BEN domain-containing protein 3; BETi - bromodomain and extra-terminal BET protein inhibitors; $C B F A 2 T 3$ - core-binding factor, runt domain, alpha subunit 2, translocated to 3; $C B L B$ - Casitas B-lineage lymphoma pro-oncogene-b; $C B S 7 / 9$ - CTCF binding motif; $C X C R-4$ - $\alpha$-chemokine receptor specific for stromal-derived-factor-1; DNMT3b - DNA methyltransferase 3 $\beta$; HOTAIRM1 - HOXA transcript antisense RNA, myeloid-specific 1; HOXA9 - homeobox protein Hox-A9; HOXA10 - homeobox protein Hox-A10; ILF2 - Interleukin enhancer-binding factor 2; ILF3 - Interleukin enhancer-binding factor 3; IRF-1 - interferon regulatory factor-1; KLF4 - Kruppel like factor 4; MCL1 - induced myeloid leukemia cell differentiation protein Mcl-1; MDS - myelodysplastic syndrome; MN1 - meningioma 1; MTCH2 - mitochondrial carrier homolog 2; MYH8 - myosin heavy chain 8; PNK - placental CD34+ cell-derived NK; ROS - reactive oxygen species; TRPM2 - transient receptor potential cation channel, subfamily $\mathrm{M}$, member 2

out upregulated the ATP-binding cassette super-family G member 2 (ABCG2) and decreased the intracellular levels of TAK-243. Thus, ABCG2 expression could be a predictor of TAK-243 sensitivity ${ }^{12}$.

CC-90009 is a novel cerebellar E3 ligase modulator, with action on AML blasts and leukemia stem cells. Using CRISPR-Cas9 technology, it was discovered that the ILF2 and ILF3 heterodimeric complex is a novel regulator of cereblon expression. Knockout of ILF2 / ILF3 reduces the production of full-length cereblon protein, and decreases the response to CC-90009. Hyperactivation of the mTOR mechanism had a protective role against the growth inhibitory effect of CC-90009 (ref. ${ }^{13}$ ).

\section{ANTITUMOR IMMUNITY}

The resistance against surveillance provided by endogenous immune cells, including natural killer (NK) cells is an issue of interest. Lymphocyte activity is negatively regulated by ubiquitin ligase Casitas B-lineage lymphoma pro-oncogene-b (CBLB) on placental CD34+ cellderived NK (PNK) cell. $C B L B$ gene was knocked out in placenta-derived CD34+ hematopoietic stem cells using the CRISPR/Cas9 system. Then, stem cells differentiated into PNK cells. The antitumor effect of CBLB knockout PNK cells was further studied in an AML (HL-60) tumor model in mice. These genetically modified PNK cells had a higher proliferative capacity and effector function ${ }^{14}$.

\section{MAINTAINING LEUKEMIC STATUS}

AML cells can have innate or adaptive resistance to the action of bromodomain and extra-terminal (BET) protein inhibitors ${ }^{15}$. The regulation of CCCTC-binding factor (CTCF) and the expression of HOX gene are involved in regulating maintenance of leukemic stem cells (LSCs) that are resistant to BET inhibitors (BETi). CRISPR-Cas9 technology was used to delete 47 base pairs of the CTCF binding motif (CBS7/9). This dowregulated HOXA9 and sensitized the BETi treatment reaction ${ }^{16}$.

\section{CELL DIFFERENTIATION}

A cell surface-based CRISPR platform was used to assess genes involved in maintaining the undifferentiated 
Table 2. The contribution of CRISPR/Cas9 technology to understanding the mechanisms of drug resistance of AML cels and overcoming them.

\begin{tabular}{|c|c|c|c|c|c|}
\hline No & $\begin{array}{l}\text { CRISPR/Cas } 9 \\
\text { contribution }\end{array}$ & Gene involved & $\begin{array}{l}\text { The mechanism of drug } \\
\text { resistance }\end{array}$ & Solutions for overcoming it & Ref. \\
\hline 1 & $\begin{array}{l}\text { genome-wide } \\
\text { screen }\end{array}$ & $\begin{array}{l}\text { LZTR1, NF1, TSC1 and TSC2 } \\
\text { - negative regulators of the } \\
\text { MAPK and MTOR mechanisms }\end{array}$ & $\begin{array}{l}\text { resistance to some FLT3 } \\
\text { inhibitors }\end{array}$ & $\begin{array}{l}\text { combining FLT3 inhibitors with } \\
\text { those of MEK }\end{array}$ & 33 \\
\hline 2 & $\begin{array}{l}\text { genome-wide } \\
\text { screen }\end{array}$ & $\begin{array}{l}\text { genes that sensitize AML } \\
\text { cells to double negative } \mathrm{T} \text { cell } \\
\text { therapy }\end{array}$ & $\begin{array}{l}\text { resistance to double negative } \\
\text { T cell-mediated cytotoxicity }\end{array}$ & $\begin{array}{l}\text { CD64 is a predictive marker for } \\
\text { response }\end{array}$ & 2 \\
\hline 3 & gene deletion & $I L-6$ & $\begin{array}{l}\text { BMSCs promote resistance } \\
\text { to chemotherapy through the } \\
\text { activation of the IL-6/STAT3/ } \\
\text { OXPHOS pathway }\end{array}$ & $\begin{array}{l}\text { IL- } 6 \text { knockout decreased the } \\
\text { ability of a line of stromal cells to } \\
\text { activate STAT3 }\end{array}$ & 34 \\
\hline 4 & gene editing & P-selectin & $\begin{array}{l}\text { E-selectin-mediated chemo- } \\
\text { resistance in vitro }\end{array}$ & the absence of P-selectin & 35 \\
\hline 5 & gene deletion & $J M J D 6$ or $T C F 7 L 2$ & BETi-persister / resistance & $\begin{array}{l}\text { knockout of both genes or the } \\
\text { treatment against multiple targets } \\
\text { of the } \beta \text {-catenin-TCF7L2-JMJD6- } \\
\text { c-Myc axis }\end{array}$ & 15 \\
\hline
\end{tabular}

BETi - bromodomain and extra-terminal BET protein inhibitors; BMSCs - bone marrow stromal cells; FLT3 - fms-like tyrosine kinase 3; IL-6 interleukin 6; MAPK - MEK - mitogen-activated protein kinases; MTOR - mechanistic target of rapamycin; TCF7L2 - transcription factor 7 - like 2; JMJD6 - bifunctional arginine demethylase and lysyl-hydroxylase JMJD6

state of leukemia cells. So, such a gene was found: RNAbinding protein ZFP36L2. It induces the mRNA of key myeloid maturation genes degradation, including the ZFP36 paralogs, and prevents terminal myeloid cell differentiation. The genetic inhibition of the ZFP36L2 gene contributes to the restoration of the mRNA stability of these targeted transcripts and constitutes triggers for myeloid differentiation in leukemia cells. But epigenomic studies done in patients with AML have found enhancer modules near ZFP36L2 that are associated with distinct AML cell states. Thus, there are coordinated epigenetic and post-transcriptional mechanisms involved in leukemic differentiation ${ }^{17}$.

CRISPR/Cas9 technology allowed the excision of the interferon regulatory factor-1 (IRF-1) gene from HL60 cells. Thus, it was found that IRF-1 is not essential for differentiation induced by all-transretinoic acid or 1,25-Dihydroxyvitamin D3, but is involved in the upregulation of $\mathrm{p} 47$ phox expression required for mature-cell ROS production in granulocyte metabolism ${ }^{18}$.

CBFA2T3 is involved in maintaining the leukemic status of the stem cell and in AML relapse. It acts by repressing retinoic acid receptor (RAR) target gene expression and inhibits the AML cell differentiation induced by all-trans-retinoic acid (ATRA). CBFA2T3 gene removal using CRISPR/Cas9 system has led to spontaneous and ATRA-induced activation of myeloid genes involved in myeloid differentiation. CBFA2T3 inhibits the early step of RAR target gene transcription and could be a new target to improve AML cell differentiation induced by ATRA (ref. $\left.{ }^{19}\right)$.

\section{CELL GROWTH AND APOPTOSIS}

The deletion of KLF4 gene using CRISPR/Cas9 technology was able to reduce cell growth and increase apoptosis in two cell lines: NB4 and MonoMac-6. Transplantation of NB4 and MonoMac-6 cells after genetically engineered modification into NSG mice resulted in prolonged overall survival. KLF4 gene loss did not decrease the sensitivity of leukemic cells to chemotherapy with products such as cytarabine and daunorubicin ${ }^{1}$.

CRISPR/Cas9 knockout library screenings have made it possible to discover and establish that SNORD42A (a small nucleolar RNA) is an important modulator for AML cell survival and proliferation in various human leukemia cell lines. Leukemic cell survival and growth needs both high-level expression of SNORD42A and U116 18S 2'-O-methylation rRNA $\left(\right.$ ref. $^{20}$ ).

\section{SELF-RENEWAL}

The depletion of the gene encoding liver kinase B1 also known as serine/threonine kinase 11 (LKB1/STK11) obtained using CRISPR/Cas9 system produced in vitro self-renewal increase of murine myeloproliferative neoplasm cells. In addition, downregulation of $L K B 1$ gene was observed in the blast phase of human myeloproliferative neoplasms. These observations lead to the conclusion that STK11 has a tumor suppressor role in myeloproliferative neoplasms ${ }^{21}$. 


\section{COMBINED PATHOPHYSIOLOGICAL MECHANISMS}

Alternative splicing (AS) events were studied in AML patients and a 15 AS event-based prognostic signature was elaborated. CRISPR-based data validated that overexpression of genes encoding RNA-binding protein 39 was involved in the higher exon inclusion of SETD5 and contributed to a poor outcome ${ }^{22}$.

The suppression of the gene encoding LIM kinase 1 obtained using CRISPR/Cas9 technology and its pharmacologic inhibition and those of its homolog LIM kinase 2 was able to diminish colony formation and proliferation rate of some AML cell lines. In addition, morphological changes suggestive of myeloid differentiation were observed. The anti-leukemic phenotype is the result of upregulation of several tumor suppressor genes and downregulation of HOXA9 targets and genes involved in mitosis ${ }^{23}$.

The CRISPR/Cas9 screen was used to study cell surface genes in a syngeneic MLL-AF9 AML murine model. Thus, it has been found that CXCR-4 (an alphachemokine receptor specific for stromal-derived-factor-1) is an important surface regulator of AML cell growth and survival. Removal of the gene that encodes it eradicated AML cells in vivo without affecting their bone marrow homing. The CXCR4 signaling system is fundamental for maintaining leukemic cell status. Loss of this signaling system results in oxidative stress and differentiation of leukemic cells in vivo ${ }^{24}$.

CRISPR activation library was used in order to better understand the regulatory mechanism of $M Y C$ expression. It allowed the identification of a new regulator - M1AP, involved in a higher induced $M Y C$ expression ${ }^{25}$.

Removal of the gene encoding transient receptor potential cation channel, subfamily M, member 2 (TRPM2) protein was performed in U937 cells (an AML model) using CRISPR/Cas9 technology. The result was inhibition of leukemic proliferation and survival and increased sensitivity to doxorubicin. The mechanisms involved were: reduced mitochondrial function, impaired cellular bioenergetic processes, decreased antioxidant response, autophagy inhibition and destabilization of ULK1 protein ${ }^{26}$.

CRISPR screen was used to find a mitochondrial gene involved in the growth of AML cells - mitochondrial outer membrane protein mitochondrial carrier homolog 2 (MTCH2). Removal of $M T C H 2$ gene has led to reduced growth and engraftment potential of stem cells, and increased differentiation. The mechanism involved was: increased nuclear pyruvate and pyruvate dehydrogenase, which has led to histone acetylation and then AML cell differentiation ${ }^{27}$.

CRISPR/Cas9 knockout screens in AML cells allowed the identification of PRC2-NSD2/3-mediated MYC regulatory axis as a drug-induced antagonistic pleiotropy mechanism. It was found that acquisition of resistance to bromodomain inhibition obtained through this mechanism leads to hypersensitivity to $B C L-2$ inhibition ${ }^{28}$.

HOXA transcript antisense RNA, myeloid-specific 1 (HOTAIRM1) is a long non-coding RNA gene with an important role in the occurrence of AML. Long term exposure to hydroquinone (a benzene metabolite) was able to induce malignant transformation of TK6 cells (HQ-MT cells). The DNMT3b knockout HQ-MT cells obtained using CRISPR/Cas9 system had promoter hypomethylation and high expression of HOTAIRM1. Long exposure to hydroquinone or benzene may increase DNMT3b expression and the promoter hypermethylation; the result is the silencing of HOTAIRMI expression, a possible tumorsuppressor ${ }^{29}$.

MiR-708 is upregulated in Hoxa9/Meis1 AML inducing cell lines and in samples obtained from AML patients. Knockout of miR-708 obtained using CRISPR/Cas9 in this AML cell model allowed to establish that miR-708 is a regulator of the Hoxa9. It is an important antagonist of the Hoxa9 phenotype but also an effector of transformation in Hoxa9/Meis1 (ref. ${ }^{30}$ ).

Genome editing using CRISPR-Cas9 allowed to obtain knock-in AML cell lines with MYH8 tail truncation mutation, R1292X. These cells had higher migration capacity, epithelial-to-mesenchymal transition, cell migration and a repression of the Raf / MAPK mechanism - indicators of a poor prognosis ${ }^{31}$.

Meningioma 1 (MN1), a co-factor of HOXA9 and $M E I S 1$, could be removed from mixed leukemia-rearranged AML cells using CRISR-Cas9 technology. Thus it was found that $\mathrm{MN} 1$ is involved in the transcription of HOXA9 and HOXA10 genes (which are important for MLL-AML), and their target genes such as BCL2, MCL1 and Survivin. Thus, MN1 could be a new target for this type of AML (ref. ${ }^{32}$ ).

\section{THERAPEUTIC RESISTANCE}

The contribution of CRISPR/Cas9 technology to understanding the mechanisms of drug resistance of AML cels and overcoming them is presented in Table 2.

About a quarter of patients with AML who are carriers of internal tandem duplication of Fms-like tyrosine kinase 3 (FLT3)-ITD or FLT3-TKD mutations develop resistance to FLT3 inhibitors. Mediators of sorafenib resistance could be identified starting from a genome-wide CRISPR screen. They are encoded by the LZTRI, NFI, $T S C 1$ or $T S C 2$ genes, and are negative regulators of the MAPK and MTOR mechanisms. The activity of these pathways was upregulated in AML cells, which showed resistance to some FLT3 inhibitors, including sorafenib. Therapeutic efficacy could be increased by combining FLT3 inhibitors with those of MEK ( ref. $^{33}$ ).

A double negative T cell bears the $\alpha \beta \mathrm{T}$ cell receptor but lacks CD4, CD8, and markers of NK cell differentiation. It was observed that blasts obtained from about $30 \%$ of AML patients are resistant to double negative T cellmediated cytotoxicity. A targeted CRISPR/Cas9 screen was used to find genes responsible for the susceptibility of AML cells to double negative T cell therapy. The level of CD64 expression showed an important correlation with the sensitivity of AML cells to double negative T cell therapy. In addition, the ectopic expression of CD64 
was able to overcome AML resistance to this therapy both in vitro and in vivo ${ }^{2}$.

Bone marrow stromal cells (BMSC) are also involved in the development of resistance to chemotherapy in AML cells. Such a human BMSC line is HS-5. IL-6 knockout in HS-5 cells (obtained using CRISPR/Cas9 technology) decreased their ability to activate STAT3, to increase mitochondrial oxidative phosphorylation, or to induce chemoresistance in AML cells. BMSCs promoted resistance to chemotherapy in these leukemic cells through the activation of the IL-6/STAT3/OXPHOS mechanism ${ }^{34}$. CRISPR-Cas9 gene editing technology also helped to estabilish that P-selectin (CD162), but not CD44, is involved in E-selectin-mediated chemo-resistance in vitro. The onset of AML occurs later when DC162 is absent from the cell surface, and sensitivity to in vivo chemotherapy is higher ${ }^{35}$.

Knockout of JMJD6 gene or of that encoding transcription factor 7-like 2 (TCF7L2), obtained using CRISPR/Cas9 was able to reverse BETi-persister / resistance. Knockout of both genes produced AML blasts death. Treatment against multiple targets of the $\beta$-cateninTCF7L2-JMJD6-c-Myc axis may reverse adaptive and innate BETi resistance, according to the results of preclinical studies that used human post-myeloproliferative neoplasm secondary AML cells ${ }^{15}$.

\section{THERAPEUTIC ADVANCES}

CD38 antigen could be a target for the treatment of AML cells. Unfortunately, it is present not only on leukemic cells, but also on NK cells, which creates difficulties regarding CD38 chimeric antigen receptor (CAR)-NK cell therapy. Using CRISPR/Cas9 system it was possible to remove $C D 38$ gene from NK cells during expansion, which led to a mean knockdown efficiency of $84 \%$. Thus, the process of NK cells fratricide decreased and the ability of new CD38 CAR-NK cells to target leukemic blasts increased $^{36}$.

The presence of the FLT3-ITD or FLT3-TKD mutation predisposes AML to relapse. Unfortunately, not all patients respond to approved FLT3 inhibitors (midostaurin and gilteritinib), and the recurrence rate under this treatment is high. Using CRISPR technology, BCL2 knockout was performed. This has synergistic effects with an approved FLT3 inhibitor. The combination between a FLT3 inhibitor and venetoclax in vitro and in vivo has validated therapeutic effect against various models of FLT3-ITD-driven AML (ref. ${ }^{37}$ ). The same technology was used to obtain exportin 1 (XPO1) knockout. It was found that the absence of this gene encoding a protein involved in protein transport is synergistic with midostaurin treatment in AML with FLT3-ITD mutation. The finding was validated using selinexor (a reversible XPO1 inhibitor) in combination with midostaurin and gilteritinib in FLT3-ITD AML cell lines and primary samples obtained from patients. This combined treatment was able to improve survival in an aggressive experimental AML model ${ }^{38}$.

An increased expression of follistatin (fst) was ob- served in human FLT3/ITD AML cells. FST gene removal using CRISPR/Cas9 inhibited AML cell growth in vitro and in vivo. Serum fst levels correlated with clinical response to quizartinib in AML patients carrying FLT3/ ITD mutations. Thus, FST could be a new target for the treatment of these patients ${ }^{39}$.

Genes that could be therapeutic targets in AML have been identified using data from a lentiviral-based genome-wide pooled CRISPR-Cas9 library along with gene knockout $(\mathrm{KO})$ dependency scores in some AML cell lines. Thus, 94 genes of interest were selected. Fortyfour of them had an already-approved medicine against the protein encoded by them. But there is no drug in development for the other 50 genes. These results can be considered a testable compendium of AML drug targets, useful for researchers in the field of drug production ${ }^{40}$. Lysine acetyltransferase KAT7 is involved in acetylation and transcriptional regulation. Using genome-wide CRISPR-Cas9 screens it was established that KAT7 loss contributed to decreased proliferation rate, increased apoptosis, and favored differentiation of AML cells carrying MLL-X gene fusions. Therefore, KAT7 could be a therapeutic target for this subtype of AML, whose prognosis is unfavorable ${ }^{41}$.

Aberrant DNA hypermethylation and overexpression of B-cell lymphoma 2 (BCL-2) gene are mechanisms that may explain treatment resistance. Combined treatment with 5-azacitidine (5-Aza) and venetoclax allowed to obtain an overall response rate of $67 \%$ in elderly AML patients. The removal of the gene encoding phorbol12-myristate-13-acetate-induced protein 1 (PMAIP1) and BCL2 binding component 3 in AML cell lines was obtained using CRISPR/Cas9 technology. This model allowed to establish that the two drugs act synergistically. AML cell apoptosis induced by Aza occurs through transcriptional induction of the proapoptotic protein PMAIP1. This induction was made by the integrated stress response mechanism ${ }^{42}$.

Enasidenib is an isocitrate dehydrogenase 2 (IDH2) mutant-specific inhibitor that reduces the transfusion requirement of anemic AML patients, as it increases human erythroid differentiation. This was observed in IDH2deficient AML cells, obtained using CRISPR technology. The action of enasidenib was mediated by protoporphyrin accumulation, stimulating heme production and increasing erythroid differentiation in CD71+ progenitors. Enasidenib coud decrease anemia severity and reduce the transfusion need ${ }^{43}$.

Lysine-specific demethylase 1 (LSD1) could be another target for AML treatment, especially in forms carrying the MLL mutation. Knockdown of genes encoding mTORC1 components obtained using CRISPR/Cas9 technology, or concomitant pharmacological inhibition of mTORC1 and LSD1 leads to a higher cell differentiation both in vitro and in vivo. Thus, a synergistic upregulation of a set of genes encoding transcription factor and terminal monocytic lineage differentiation was observed. This dual pharmacological inhibition could be investigated in early phase clinical trials ${ }^{44}$. 


\section{CONCLUSION}

Progress in understanding the pathogenesis of AML is dependent on advanced methods of molecular biology. CRISPR/Cas9 technology allows DNA modification through gene insertions and deletions. Thus, the function of each gene can be verified and potential new therapeutic targets can be obtained.

Some notable therapeutic outcomes are: improvement in the therapeutic efficacy of sorafenib could be obtained by combining FLT3 inhibitors with those of MEK; the combination between a FLT3 inhibitor and venetoclax is synergistic against various models of FLT3-ITD-driven AML; selinexor in combination with midostaurin and gilteritinib was able to improve survival in an aggressive experimental AML model; the removal of CD38 gene from NK cells decreased the process of fratricide and increased the ability of new CD38 CAR-NK cells to target leukemic blasts; 5-Aza and venetoclax act synergistically and allowed to improve overall response rate in elderly AML patients; enasidenib could decrease anemia severity and reduce the transfusion need.

New therapeutic targets could be: FST gene (its removal inhibited AML cell growth), lysine acetyltransferase KAT7 (its deletion decreased proliferation rate, increased apoptosis, and favored differentiation of AML cells carrying MLL-X gene fusions), and $L S D 1$ (concomitant pharmacological inhibition of mTORC1 and LSD1 leads to a higher cell differentiation).

\section{Search strategy and selection criteria}

Strategy research aimed at analyzing the contribution of CRISPR/Cas9 technology to improving knowledge of the pathogenesis of acute myeloid leukemia and finding new therapeutic targets. Scientific articles published in PubMed and Web of Science databases in the last five years, prior to 31.03.2021 were searched, using the terms "acute myeloid leukemia" and "CRISPR".

\section{ABBREVIATIONS}

AML, acute myeloid leukemia; ATRA, all-trans-retinoic acid; AS, alternative splicing; ABCG2, ATP-binding cassette super-family $\mathrm{G}$ member 2; 5-Aza, 5-azacitidine; BCL-2, B-cell lymphoma 2; BEND3, BEN domain-containing protein 3 ; BET, bromodomain and extra-terminal; BETi, BET inhibitors; BMSC, bone marrow stromal cells; CBLB, Casitas B-lineage lymphoma pro-oncogene-b; CTCF, CCCTC-binding factor; CAR, chimeric antigen receptor; CRISPR, clustered regularly interspaced short palindromic repeats; Cas9, CRISPR-associated protein 9; CBS7/9, CTCF binding motif; XPO1, exportin 1; FLT3, Fms-like tyrosine kinase 3; fst, follistatin; HSPCs, hematopoietic stem and progenitor cells; HOTAIRM1, HOXA transcript antisense RNA, myeloid-specific 1; huCB, human cord blood; iPSC, induced pluripotent stem cells; IDH2, isocitrate dehydrogenase 2; KMT2Ar, KMT2A rearrangements; KO, knockout; LSCs, leukemic stem cells; LSD1, lysine-specific demethylase 1; HQ-MT cells, malignant transformation of TK6 cells; MTCH2, membrane protein mitochondrial carrier homolog 2; MN1, meningioma 1; MLL, mixed lineage leukemia; MA9, mixed lineage leukemia-AF9; NK, natural killer; PMAIP1, phorbol-12-myristate-13-acetate-induced protein 1; PNK, placental CD34+ cell-derived NK; CD162, P-selectin; RAR, retinoic acid receptor; LKB1/Stk11, serine/threonine kinase 11; sgRNAs, "single guide RNAs"; TCF7L2, transcription factor 7-like 2; TRPM2, transient receptor potential cation channel, subfamily M, member 2 .

Author contributions: RGM and DT contributed equally to the selection of articles, the elaboration of the manuscript, its correction and the final approval.

Conflict of interest statement: The authors declare that there are no conflicts of interest regarding the publication of this article.

\section{REFERENCES}

1. Lewis AH, Bridges CS, Punia VS, Cooper AFJ, Puppi M, Lacorazza HD Krüppel-like factor 4 promotes survival and expansion in acute myeloid leukemia cells. Oncotarget 2021;12(4):255-67.

2. Soares F, Chen B, Lee JB, Ahmed M, Ly D, Tin E, Kang H, Zeng Y, Akhtar $\mathrm{N}$, Minden MD, He H, Zhang L. CRISPR screen identifies genes that sensitize AML cells to double negative T cell therapy. Blood 2020 Dec 3. [Epub ahead of print] doi: 10.1182/blood.2019004108

3. Pasquer $\mathrm{H}$, Tostain M, Kaci N, Roux B, Benajiba L. Descriptive and Functional Genomics in Acute Myeloid Leukemia (AML): Paving the Road for a Cure. Cancers (Basel) 2021;13(4):748.

4. Singh A. Modulating Gene Expression - Abridging the RNAi and CRISPR-Cas9 Technologies. In: Singh A, Khan MW. Modulating Gene Expression. IntechOpen. http://dx.doi.org/10.5772/intechopen.84229

5. García-Tuñon I, Vuelta E, Pérez-Ramos S, Hernández-Rivas JM, Méndez L, Herrero M, Sanchez-Martin M. CRISPR-ERA for switching off (onco) genes. In: Singh A, Khan MW. Modulating Gene Expression. IntechOpen. http://dx.doi.org/10.5772/intechopen.80245

6. Liu Q, Garcia M, Wang S, Chen CW. Therapeutic Target Discovery Using High-Throughput Genetic Screens in Acute Myeloid Leukemia. Cells 2020;9(8):1888.

7. Wang T, Pine AR, Kotini AG, Yuan H, Zamparo L, Starczynowski DT, Leslie C, Papapetrou EP. Sequential CRISPR gene editing in human iPSCs charts the clonal evolution of myeloid leukemia and identifies early disease targets. Cell Stem Cell 2021. [Epub ahead of print] doi: 10.1016/j.stem.2021.01.011

8. Schieber M, Marinaccio C, Bolanos LC, Haffey WD, Greis KD, Starczynowski DT, Crispino JD. FBXO11 is a candidate tumor suppressor in the leukemic transformation of myelodysplastic syndrome. Blood Cancer J 2020;10(10):98.

9. Barwe SP, Sidhu I, Kolb EA, Gopalakrishnapillai A. Modeling Transient Abnormal Myelopoiesis Using Induced Pluripotent Stem Cells and CRISPR/Cas9 Technology. Mol Ther Methods Clin Dev 2020;19:201-9.

10. Sarrou E, Richmond L, Carmody RJ, Gibson B, Keeshan K. CRISPR Gene Editing of Murine Blood Stem and Progenitor Cells Induces MLL-AF9 Chromosomal Translocation and MLL-AF9 Leukaemogenesis. Int J Mol Sci 2020;21(12):4266.

11. Secker KA, Bruns L, Keppeler H, Jeong J, Hentrich T, SchulzeHentrich JM, Mankel B, Fend F, Schneidawind D, Schneidawind C. Only Hematopoietic Stem and Progenitor Cells from Cord Blood Are Susceptible to Malignant Transformation by MLL-AF4 Translocations. Cancers (Basel) 2020;12(6):1487.

12. Barghout SH, Aman A, Nouri K, Blatman Z, Arevalo K, Thomas GE, MacLean N, Hurren R, Ketela T, Saini M, Abohawya M, Kiyota T, AlAwar R, Schimmer AD. A genome-wide CRISPR/Cas9 screen in acute myeloid leukemia cells identifies regulators of TAK-243 sensitivity. JCI Insight 2021;6(5):141518. 
13. Surka C, Jin L, Mbong N, Lu CC, Jang IS, Rychak E, Mendy D, Clayton T, Tindall E, Hsu C, Fontanillo C, Tran E, Contreras A, Ng SWK, Matyskiela M, Wang K, Chamberlain P, Cathers B, Carmichael J, Hansen J, Wang JCY, Minden MD, Fan J, Pierce DW, Pourdehnad M, Rolfe M, LopezGirona A, Dick JE, Lu G. CC-90009, a novel cereblon E3 ligase modulator, targets acute myeloid leukemia blasts and leukemia stem cells. Blood 2021;137(5):661-77.

14. Guo X, Mahlakõiv T, Ye Q, Somanchi S, He S, Rana H, DiFiglia A, Gleason J, van der Touw W, Hariri R, Zhang X. CBLB ablation with CRISPR/Cas9 enhances cytotoxicity of human placental stem cellderived NK cells for cancer immunotherapy. J Immunother Cancer 2021;9(3):e001975.

15. Saenz DT, Fiskus W, Mill CP, Perera D, Manshouri T, Lara BH, Karkhanis V, Sharma S, Horrigan SK, Bose P, Kadia TM, Masarova L, DiNardo CD, Borthakur G, Khoury JD, Takahashi K, Bhaskara S, Lin CY, Green MR, Coarfa C, Crews CM, Verstovsek S, Bhalla KN. Mechanistic basis and efficacy of targeting the $\beta$-catenin-TCF7L2-JMJD6-c-Myc axis to overcome resistance to BET inhibitors. Blood 2020;135(15):1255-69.

16. Zha J, Lai Q, Deng M, Shi P, Zhao H, Chen Q, Wu H, Xu B. Disruption of CTCF Boundary at HOXA Locus Promote BET Inhibitors Therapeutic Sensitivity in Acute Myeloid Leukemia. Stem Cell Rev Rep 2020;16(6):1280-91.

17. Wang E, Zhou H, Nadorp B, Cayanan G, Chen X, Yeaton AH, Nomikou S, Witkowski MT, Narang S, Kloetgen A, Thandapani P, Ravn-Boess N Tsirigos A, Aifantis I. Surface antigen-guided CRISPR screens identify regulators of myeloid leukemia differentiation. Cell Stem Cell 2021;28(4):718-31.e6.

18. Zhu Z, Yue J, Yen A. Depleting interferon regulatory factor-1(IRF-1) with CRISPR/Cas9 attenuates inducible oxidative metabolism without affecting RA-induced differentiation in HL-60 human AML cells. FASEB Bioadv 2020;2(6):354-64.

19. Steinauer N, Guo C, Zhang J. The transcriptional corepressor CBFA2T3 inhibits all- trans-retinoic acid-induced myeloid gene expression and differentiation in acute myeloid leukemia. J Biol Chem 2020;295(27):8887-900.

20. Pauli C, Liu Y, Rohde C, Cui C, Fijalkowska D, Gerloff D, Walter C, Krijgsveld J, Dugas M, Edemir B, Pabst C, Müller LP, Zhou F, MüllerTidow C. Site-specific methylation of $18 \mathrm{~S}$ ribosomal RNA by SNORD42A is required for acute myeloid leukemia cell proliferation. Blood 2020;135(23):2059-70.

21. Marinaccio $C$, Suraneni $P$, Celik $H$, Volk $A$, Wen $Q J$, Ling $T$, Bulic M, Lasho T, Koche RP, Famulare CA, Farnoud N, Stein B, Schieber M, Gurbuxani S, Root DE, Younger ST, Hoffman R, Gangat N, Ntziachristos P, Chandel NS, Levine RL, Rampal RK, Challen GA, Tefferi A, Crispino JD. LKB1/STK11 is a tumor suppressor in the progression of myeloproliferative neoplasms. Cancer Discov 2021. [Epub ahead of print] doi: 10.1158/2159-8290.CD-20-1353

22. Jin P, Tan Y, Zhang W, Li J, Wang K. Prognostic alternative mRNA splicing signatures and associated splicing factors in acute myeloid leukemia. Neoplasia 2020;22(9):447-57.

23. Jensen PJ, Carlet M, Schlenk RF, Weber A, Kress J, Brunner I, Słabicki M, Grill G, Weisemann S, Cheng YY, Jeremias I, Scholl C, Fröhling S. Requirement for LIM kinases in acute myeloid leukemia. Leukemia 2020;34(12):3173-85.

24. Ramakrishnan R, Peña-Martínez $P$, Agarwal $P$, Rodriguez-Zabala $M$, Chapellier M, Högberg C, Eriksson M, Yudovich D, Shah M, Ehinger $M$, Nilsson B, Larsson J, Hagström-Andersson A, Ebert BL, Bhatia R, Järås M. CXCR4 Signaling Has a CXCL12-Independent Essentia Role in Murine MLL-AF9-Driven Acute Myeloid Leukemia Cell Rep 2020;31(8):107684

25. Yamamoto A, Kurata M, Onishi I, Sugita K, Matsumura M, Ishibash S, Ikeda M, Yamamoto K, Kitagawa M. CRISPR screening identifies M1AP as a new MYC regulator with a promoter-reporter system. PeerJ 2020;8:e9046.

26. Chen SJ, Bao L, Keefer K, Shanmughapriya S, Chen L, Lee J, Wang JF, Zhang XQ, Hirschler-Laszkiewicz I, Merali S, Merali C, Imamura Y, Dovat S, Madesh M, Cheung JY, Wang HG, Miller BA. Transient receptor potential ion channel TRPM2 promotes AML proliferation and survival through modulation of mitochondrial function, ROS, and autophagy. Cell Death Dis 2020;11(4):247.

27. Khan DH, Mullokandov M, Wu Y, Voisin V, Gronda M, Hurren R, Wang X, MacLean N, Jeyaraju DV, Jitkova Y, Xu GW, Laister R, Seneviratne A, Blatman ZM, Ketela T, Bader GD, Marhon SA, De Carvalho DD,
Minden MD, Gross A, Schimmer AD. Mitochondrial carrier homolog 2 is necessary for AML survival. Blood 2020;136(1):81-92.

28. Lin KH, Rutter JC, Xie A, Pardieu B, Winn ET, Bello RD, Forget A, Itzykson R, Ahn YR, Dai Z, Sobhan RT, Anderson GR, Singleton KR, Decker AE, Winter PS, Locasale JW, Crawford L, Puissant A, Wood KC. Using antagonistic pleiotropy to design a chemotherapy-induced evolutionary trap to target drug resistance in cancer. Nat Genet 2020;52(4):408-17.

29. Zhang H, Yuan Q, Pan Z, Ling X, Tan Q, Wu M, Zheng D, Xie P, Xie D, Liu L. Up-regulation of DNMT3b contributes to HOTAIRM1 silencing via DNA hypermethylation in cells transformed by long-term exposure to hydroquinone and workers exposed to benzene. Toxicol Lett 2020;322:12-9.

30. Schneider E, Pochert N, Ruess C, MacPhee L, Escano L, Miller C, Krowiorz K, Malmberg ED, Heravi-Moussavi A, Lorzadeh A, Ashouri A, Grasedieck S, Sperb N, Kopparapu PK, Iben S, Staffas A, Xiang P, Rösler R, Kanduri M, Larsson E, Fogelstrand L, Döhner H, Döhner K, Wiese S, Hirst M, Humphries RK, Palmqvist L, Kuchenbauer F, Rouhi A. MicroRNA-708 is a novel regulator of the Hoxa9 program in myeloid cells. Leukemia 2020;34(5):1253-65.

31. Park H, Kim D, Kim D, Park J, Koh Y, Yoon SS. Truncation of MYH8 tail in AML: a novel prognostic marker with increase cell migration and epithelial-mesenchymal transition utilizing RAF/MAPK pathway. Carcinogenesis 2020;41(6):817-27.

32. Sharma A, Jyotsana N, Gabdoulline R, Heckl D, Kuchenbauer F, Slany RK, Ganser A, Heuser M. Meningioma 1 is indispensable for mixed lineage leukemia-rearranged acute myeloid leukemia. Haematologica 2020;105(5):1294-305.

33. Damnernsawad A, Bottomly D, Kurtz SE, Eide CA, McWeeney SK, Tyner JW, Nechiporuk T. Genome-wide CRISPR screen identifies regulators of MAPK and MTOR pathways mediating sorafenib resistance in acute myeloid leukemia. Haematologica 2020 Dec 30. [Epub ahead of print] doi: 10.3324/haematol.2020.257964

34. Hou D, Wang B, You R, Wang X, Liu J, Zhan W, Chen P, Oin T, Zhang X, Huang $\mathrm{H}$. Stromal cells promote chemoresistance of acute myeloid leukemia cells via activation of the IL-6/STAT3/OXPHOS axis. Ann Transl Med 2020;8(21):1346.

35. Erbani J, Tay J, Barbier V, Levesque JP, Winkler IG. Acute Myeloid Leukemia Chemo-Resistance Is Mediated by E-selectin Receptor CD162 in Bone Marrow Niches. Front Cell Dev Biol 2020;8:668.

36. Gurney M, Stikvoort A, Nolan E, Kirkham-McCarthy L, Khoruzhenko S, Shivakumar R, Zweegman S, Van de Donk NWCJ, Mutis T, Szegezdi E, Sarkar S, O'Dwyer M. CD38 knockout natural killer cells expressing an affinity optimized CD38 chimeric antigen receptor successfully target acute myeloid leukemia with reduced effector cell fratricide. Haematologica 2020 Dec 30. [Epub ahead of print] doi: 10.3324/ haematol.2020.271908

37. Brinton LT, Zhang P, Williams K, Canfield D, Orwick S, Sher S, Wasmuth R, Beaver L, Cempre C, Skinner J, Cannon M, Govande M, Harrington B, Lehman A, Byrd JC, Lapalombella R, Blachly JS. Synergistic effect of BCL2 and FLT3 co-inhibition in acute myeloid leukemia. J Hematol Oncol 2020;13(1):139.

38. Brinton LT, Sher S, Williams K, Canfield D, Orwick S, Wasmuth R, Cempre C, Skinner J, Lehman A, Blachly JS, Byrd JC, Lapalombella R. Cotargeting of XPO1 Enhances the Antileukemic Activity of Midostaurin and Gilteritinib in Acute Myeloid Leukemia. Cancers (Basel) 2020;12(6):1574

39. He BL, Yang N, Man CH, Ng NKL, Cher CY, Leung HC, Kan LLH, Cheng BYL, Lam SSY, Wang MLL, Zhang CX, Kwok H, Cheng G, Sharma R, Ma $A C H$, So CWE, Kwong YL, Leung AYH. Follistatin is a novel therapeutic target and biomarker in FLT3/ITD acute myeloid leukemia. EMBO Mol Med 2020;12(4):e10895.

40. Zhou Y, Takacs GP, Lamba JK, Vulpe C, Cogle CR. Functional Dependency Analysis Identifies Potential Druggable Targets in Acute Myeloid Leukemia. Cancers (Basel) 2020;12(12):3710.

41. Au YZ, Gu M, De Braekeleer E, Gozdecka M, Aspris D, Tarumoto Y, Cooper J, Yu J, Ong SH, Chen X, Tzelepis K, Huntly BJP, Vassiliou G, Yusa K. KAT7 is a genetic vulnerability of acute myeloid leukemias driven by MLL rearrangements. Leukemia 2020 Aug 6. [Epub ahead of print] doi: 10.1038/s41375-020-1001-z

42. Jin S, Cojocari D, Purkal JJ, Popovic R, Talaty NN, Xiao Y, Solomon LR, Boghaert ER, Leverson JD, Phillips DC. 5-Azacitidine Induces NOXA to Prime AML Cells for Venetoclax-Mediated Apoptosis. Clin Cancer Res 2020;26(13):3371-83. 
43. Dutta R, Zhang TY, Köhnke T, Thomas D, Linde M, Gars M, Stafford M, Kaur S, Nakauchi Y, Yin R, Azizi A, Narla A, Majeti R. Enasidenib drives human erythroid differentiation independently of isocitrate dehydrogenase 2. J Clin Invest 2020;130(4):1843-9.
44. Deb G, Wingelhofer B, Amaral FMR, Maiques-Diaz A, Chadwick JA, Spencer GJ, Williams EL, Leong HS, Maes T, Somervaille TCP. Pre-clinical activity of combined LSD1 and mTORC1 inhibition in MLL-translocated acute myeloid leukaemia. Leukemia 2020;34(5):1266-77. 